\title{
Entre Rede e Renda
}

\section{Renascença: diásporas}

sociais no Cariri

Paraibano

\section{Between Network and Income \\ Renascença: social diasporas in \\ Cariri Paraibano}

Rogério D Avila Ortiz'

ORCID: https://orcid.org/0000-0002-6543-3021

As fotografias fazem parte do estudo que procura ressaltar a experiência do encontro com a artesã Donna Liu, a mestra em renda renascença Marlene Leopoldino e o estilista Romero Sousa e comprova como a potência de materiais, técnicas, modelagens, ambientes, corpos e percepções pode expandir o conceito de "artesanato" e problematizar o estudo da forma e da estética, ativando pequenas percepções.

1 Mestre em Comunicação e Semiótica pela Pontifícia Universidade Católica de São Paulo (PUC-SP). Atua com fotografia e audiovisual na moda, na dança e nas artes plásticas. Doutorando em Comunicação e Semiótica mesma universidade. E-mail: contato@rogerioortiz.com.br. Lattes: http://lattes. cnpq.br/6968153953321993 
ENSAIO FOTOGRÁFICO DONNA LIU
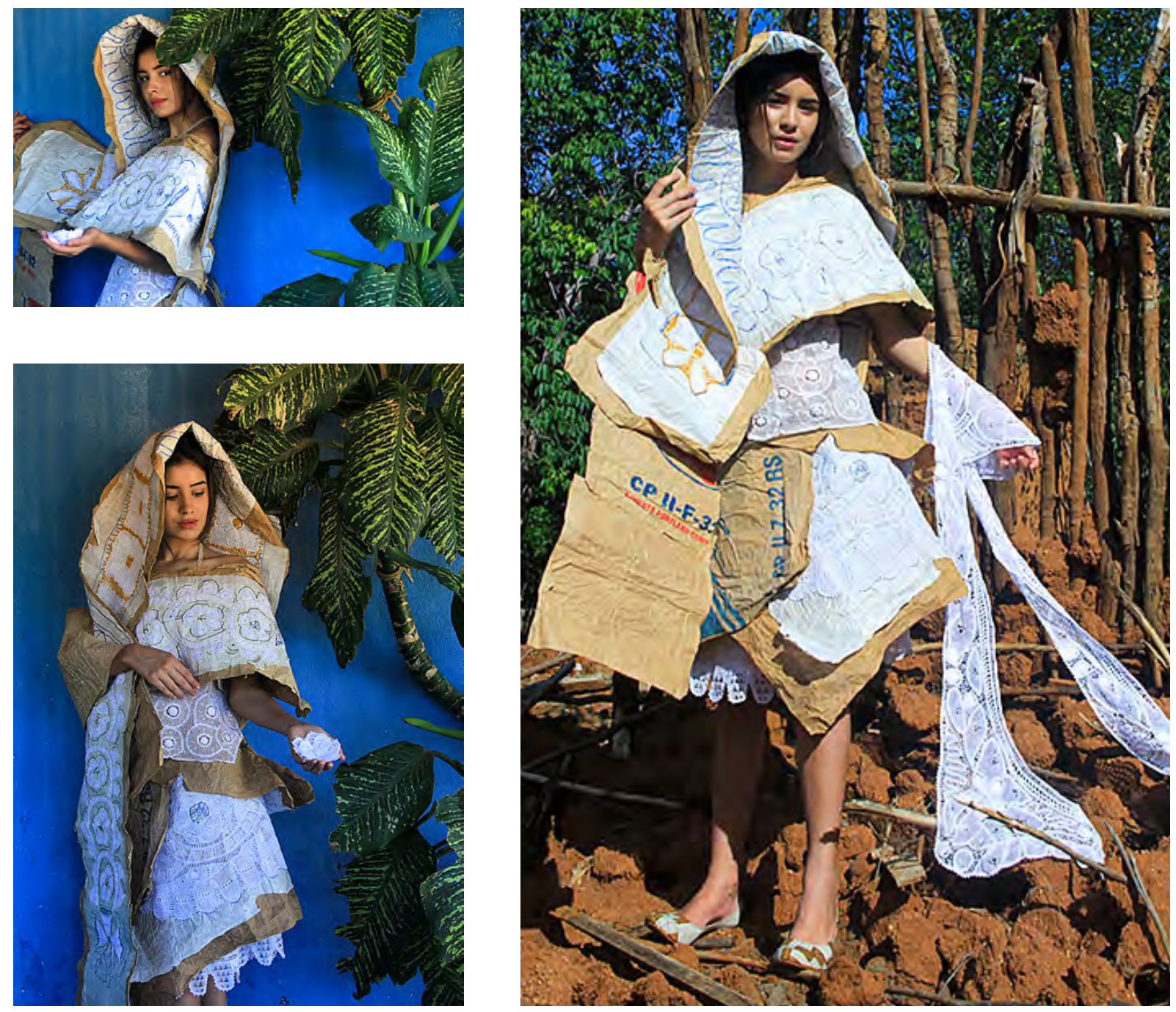

阫

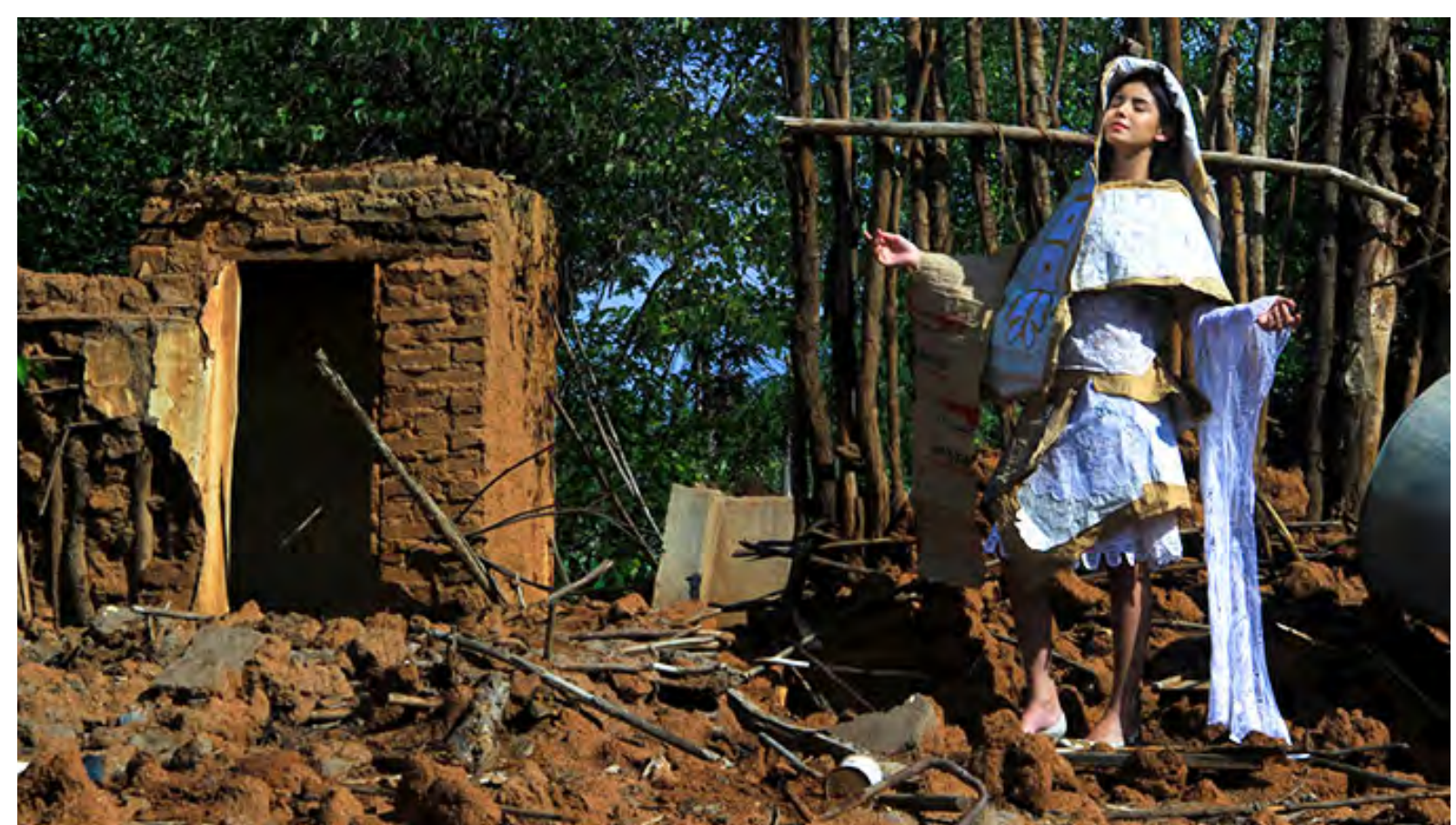





FONTE: ORTIZ, Rogério. Imagens obtidas durante pesquisa sobre renda renascença, em parceira com a artesã Donna Liu, a mestre em renda renascença Marlene Leopoldino e o estilista Romero Sousa e a performer Renata Quirino. Cariri Paraibano, Paraíba, em maio de 2018. 
ENSAIO FOTOGRÁFICO DONNA LIU

FONTE: ORTIZ, Rogério. Imagens obtidas durante pesquisa sobre renda renascença, em parceira com a artesã Donna Liu, o estilista Romero Sousa e a performer Renata Quirino. Cariri Paraibano, Paraíba, em maio de 2018.
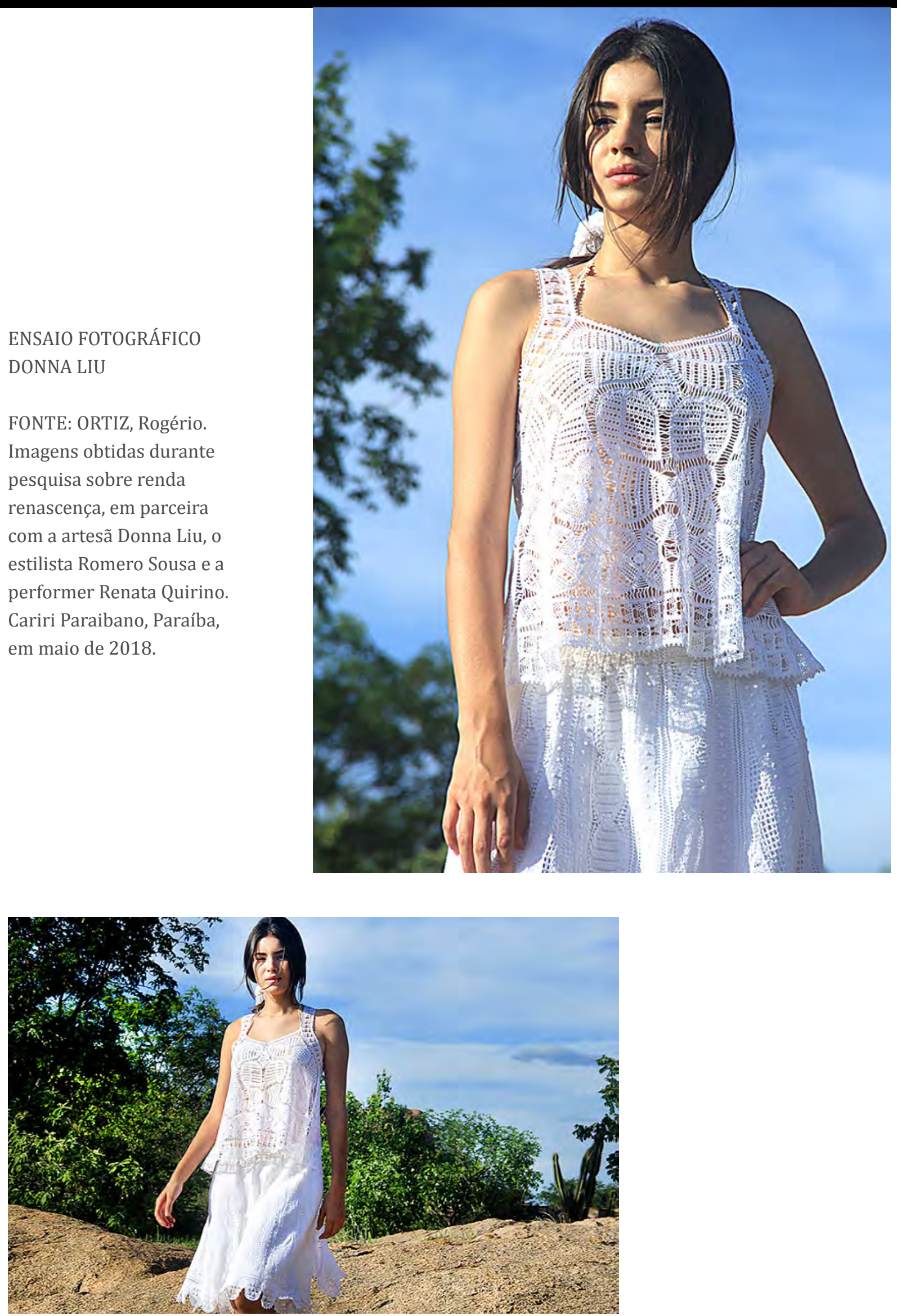
ENSAIO FOTOGRÁFICO MARLENE LEOPOLDINO
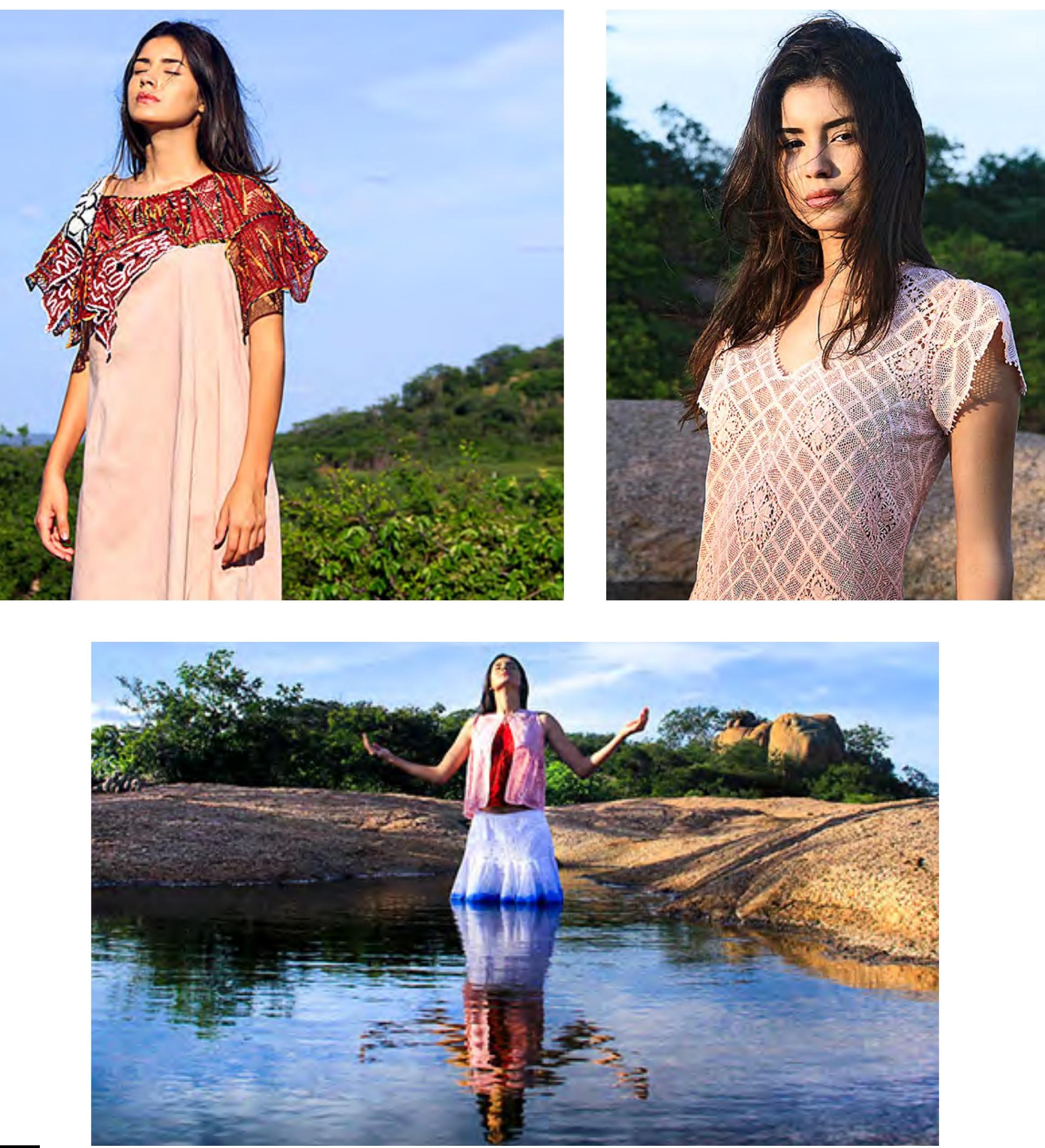

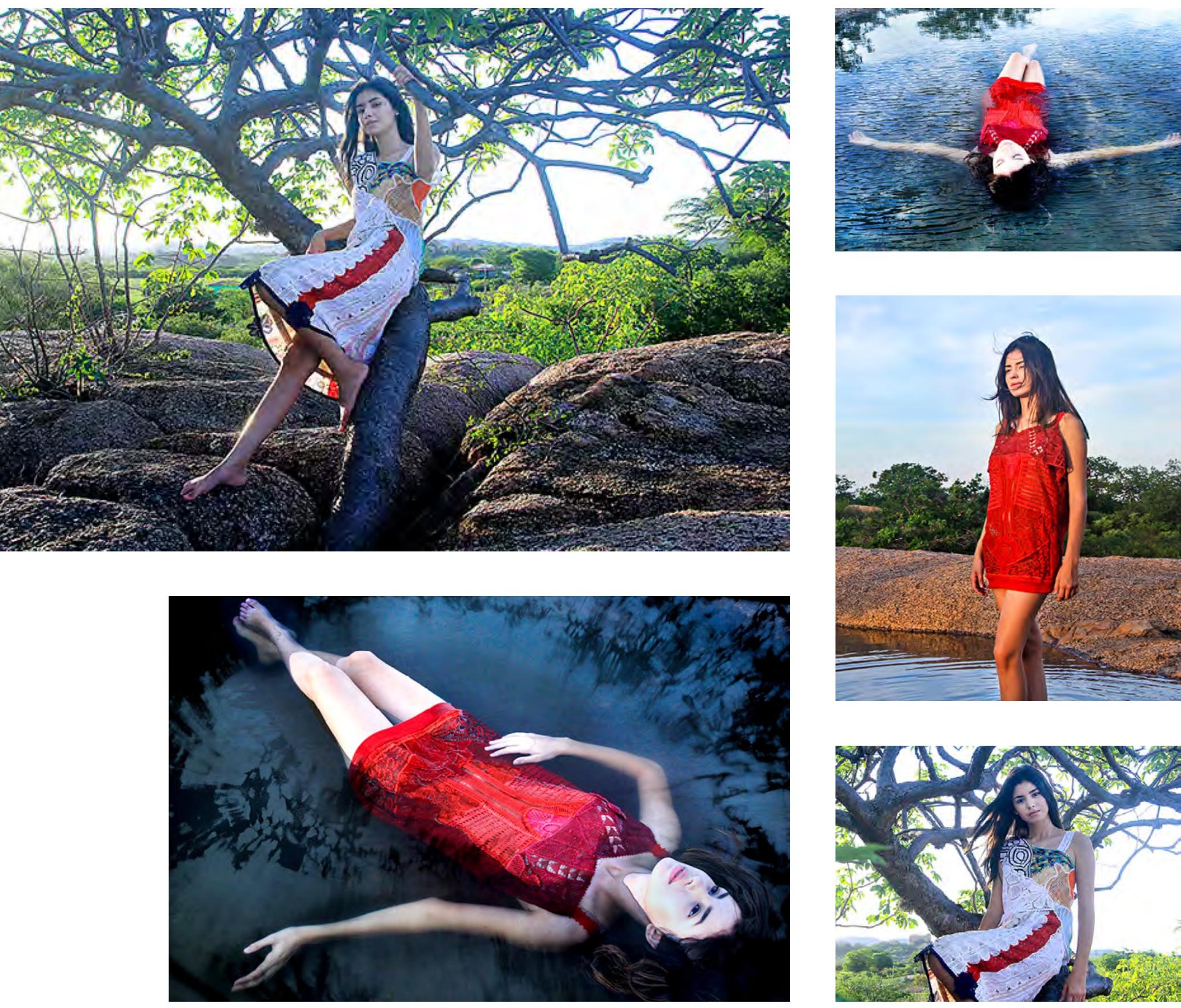

FONTE: ORTIZ, Rogério. Imagens obtidas durante pesquisa sobre renda renascença, em parceira com a mestre em renda renascença Marlene Leopoldino, o estilista Romero Sousa e a performer Renata Quirino. Cariri Paraibano, Paraíba, em maio de 2018.

\section{Agradecimentos}

Djanete Figueirêdo, Neudenis e Wagner Monteiro. 


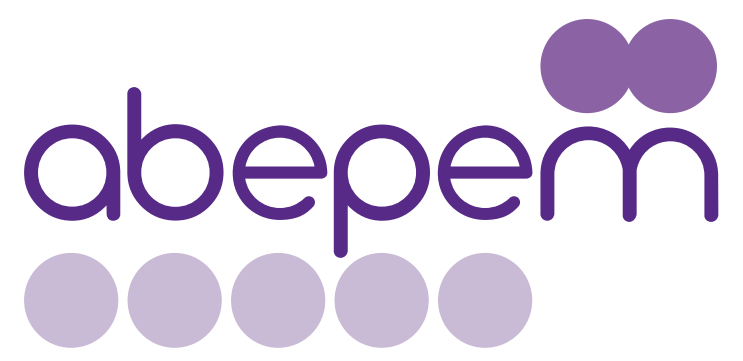

ASSOCIAÇÃO BRASILEIRA DE ESTUDOS E PESOUISAS EM MODA 